\title{
Dielectric constant and density of aqueous alkali halide solutions by molecular dynamics: A force field assessment
}

Cite as: J. Chem. Phys. 152, 164502 (2020); https://doi.org/10.1063/1.5144991

Submitted: 13 January 2020 . Accepted: 29 March 2020 . Published Online: 22 April 2020

Denis Saric (D), Maximilian Kohns (D), and Jadran Vrabec (D)
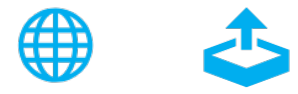

\section{ARTICLES YOU MAY BE INTERESTED IN}

Bulk viscosity of liquid noble gases

The Journal of Chemical Physics 152, 094503 (2020); https://doi.org/10.1063/1.5142364

Recent developments in the general atomic and molecular electronic structure system The Journal of Chemical Physics 152, 154102 (2020); https://doi.org/10.1063/5.0005188

Residual entropy model for predicting the viscosities of dense fluid mixtures

The Journal of Chemical Physics 152, 164104 (2020); https://doi.org/10.1063/5.0002242

\section{Lock-in Amplifiers up to $600 \mathrm{MHz}$}
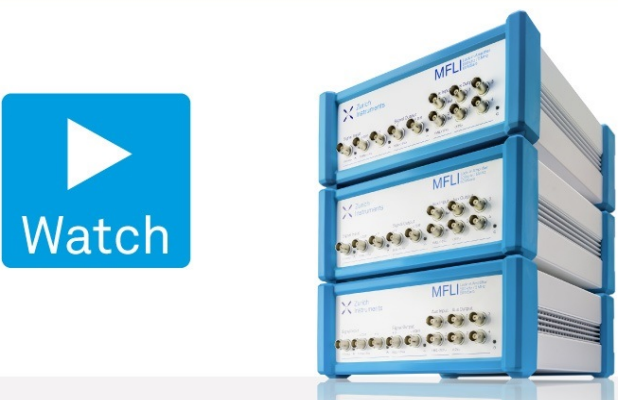


\title{
Dielectric constant and density of aqueous alkali halide solutions by molecular dynamics: A force field assessment
}

\author{
Cite as: J. Chem. Phys. 152, 164502 (2020); doi: 10.1063/1.5144991 \\ Submitted: 13 January 2020 - Accepted: 29 March 2020 • \\ Published Online: 22 April 2020

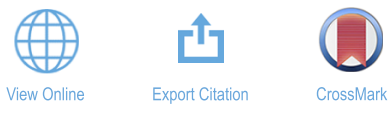

Denis Saric, (D) Maximilian Kohns, ${ }^{2}$ (D) and Jadran Vrabec ${ }^{3, a)}$ (D)

\section{AFFILIATIONS}

${ }^{1}$ Thermodynamics and Energy Technology, University of Paderborn, 33098 Paderborn, Germany

${ }^{2}$ Laboratory of Engineering Thermodynamics, Technische Universität Kaiserslautern, 67633 Kaiserslautern, Germany

${ }^{3}$ Thermodynamics and Process Engineering, Technical University Berlin, 10587 Berlin, Germany

\author{
a) Author to whom correspondence should be addressed: vrabec@tu-berlin.de
}

\begin{abstract}
The concentration dependence of the dielectric constant and the density of 11 aqueous alkali halide solutions $(\mathrm{LiCl}, \mathrm{NaCl}, \mathrm{KCl}, \mathrm{RbCl}, \mathrm{CsCl}$, LiI, NaI, KI, CsI, KF, and CsF) is investigated by molecular simulation. Predictions using eight non-polarizable ion force fields combined with the TIP4P/ $\varepsilon$ water model are compared to experimental data. The influence of the water model and the temperature on the results for the $\mathrm{NaCl}$ brine are also addressed. The TIP4P/E water model improves the accuracy of dielectric constant predictions compared to the SPC/E water model. The solution density is predicted well by most ion models. Almost all ion force fields qualitatively capture the decline of the dielectric constant with the increase of concentration for all solutions and with the increase of temperature for $\mathrm{NaCl}$ brine. However, the sampled dielectric constant is mostly in poor quantitative agreement with experimental data. These results are related to the microscopic solution structure, ion pairing, and ultimately the force field parameters. Ion force fields with excessive contact ion pairing and precipitation below the experimental solubility limit generally yield higher dielectric constant values. An adequate reproduction of the experimental solubility limit should therefore be a prerequisite for further investigations of the dielectric constant of aqueous electrolyte solutions by molecular simulation.
\end{abstract}

Published under license by AIP Publishing. https://doi.org/10.1063/1.5144991

\section{INTRODUCTION}

The unusually high dielectric constant of water under standard conditions of temperature and pressure $(\varepsilon=78.5)^{1}$ is one of its anomalies, ${ }^{2}$ which partly explains the dissolution of $1: 1$ salts in liquid water at low and moderate concentrations into single ions by preventing their aggregation into crystals. ${ }^{3}$ A substantial drop of the dielectric constant, usually caused by increasing temperature or salt concentration, may lead to the formation of ion pairs as a stable species in aqueous alkali halide solutions. ${ }^{4}$

Despite its significance, the dielectric constant of even the simplest aqueous monovalent salt solutions is poorly studied by experiment and sufficiently available only for 11 of the 20 alkali halide brines. ${ }^{5-19}$ In fact, the dielectric constant is not directly measurable in the laboratory. ${ }^{20}$ It has to be extrapolated from the frequency-dependent dielectric constant in a non-trivial procedure, which requires elaborate measurement instruments, dielectric relaxation models, and a complex estimation of model parameters. ${ }^{21-23}$

An alternative to access this property, which was widely employed for water in the past three decades, is molecular modeling and simulation. The quality of the underlying force field models for solvent and solutes plays the central role for the accuracy of predictions with this approach. However, an extensive computational effort is required for a statistically sound sampling of the dielectric constant even for pure water.

Water and ions are primarily modeled by non-polarizable Lennard-Jones (LJ) sites with superimposed point charges. The temperature dependence of the dielectric constant of water ${ }^{27}$ or the recently found anomalously low dielectric constant of confined water ${ }^{28}$ was qualitatively reproduced with these simple 
models. However, the quantitative accuracy of such predictions is rather disappointing.

Commonly employed water models in studies of aqueous electrolyte solutions, such as SPC/E $(\varepsilon=70.7 \text { at } 298 \mathrm{~K})^{29}$ or TIP4P $(\varepsilon=53$ at $293 \mathrm{~K}),{ }^{30}$ underestimate the dielectric constant. The $\mathrm{TIP} 4 \mathrm{P} / 2005^{31}$ water model, despite its superiority over other nonpolarizable potentials, ${ }^{32}$ misses the dielectric constant by about $25 \%$ $(\varepsilon=58$ at $298 \mathrm{~K})$. The general failure of non-polarizable water models in dielectric constant simulations was essentially attributed to the application of the same partial charges to empirically fit two distinct water molecule properties (potential energy and dipole moment).

In the search for optimal force field parameters for alkali halide ions, low concentration experimental data have mostly been used in fitting procedures. ${ }^{34-41}$ For example, the hydration free energy of the ions at infinite dilution was a popular choice among many groups. $^{34-39}$ In an attempt to achieve reasonable predictions for the concentration range where cation-anion interactions become important, crystal properties ${ }^{37,42-44}$ or activity derivatives ${ }^{39,42,43}$ were considered. For a more comprehensive discussion of common parametrization strategies employed for molecular modeling of aqueous electrolyte solutions, see the review of Nezbeda et al. ${ }^{45}$

In general, however, these strategies yield unsatisfactory predictions for solution properties, such as density, ${ }^{46}$ water self-diffusion coefficient, ${ }^{47}$ or salt activity. ${ }^{48,49}$ In fact, the underprediction of the solubility limit of alkali halide salts, ${ }^{45,50-54}$ resulting in excessive ion pairing ${ }^{55-57}$ and/or premature crystallization, ${ }^{58-60}$ is a wellknown problem of non-polarizable ion force fields. The cause may lie in unbalanced force field parameters. ${ }^{58,61}$ As crystallization is a slow process that takes place on time scales much longer than those typically accessed with molecular simulation, it is possible that many reported simulation results actually do not correspond to equilibrium states.

An accurate prediction of basic solution properties, such as density, does not only serve as an indication for an adequate representation of the microscopic structure ${ }^{62}$ but also is necessary to correctly predict other properties. ${ }^{63}$ The lack of experimental dielectric constant data, the inaccuracy of water models for dielectric constant predictions, and generally inadequate ion force fields may explain why the dielectric constant of monovalent salt solutions was rarely studied with molecular simulation. After all, the prospect of dielectric constant investigations has recently improved dramatically by the development of water force fields parametrized to the dielectric constant (such as TIP4P/ $/ \varepsilon^{64}$ or TIP4Q ${ }^{65}$ ), methods for implicitly accounting for polarizability of non-polarizable models (such as charge scaling ${ }^{66}$ ), and sufficient computational power for long simulations that are required for the dielectric constant sampling. A more detailed review of current trends in molecular modeling and simulation of aqueous electrolyte solutions was provided by Smith et al.

There are only a few studies concerning dielectric constant calculations of aqueous alkali halide solutions by simulation. ${ }^{43,68-72}$ Ion models used in these studies generally predict the decrease of the dielectric constant with the increase of salt concentration qualitatively well but underestimate the experimental values quantitatively. For example, Pethes ${ }^{70}$ simulated the dielectric constant, density, and self-diffusion coefficient of water and ions using 29 ion force fields for $\mathrm{LiCl}$ up to the experimental solubility limit of the according brine. In her study, most of the ion force fields overestimated the experimental dielectric constant at moderate concentrations. In a recent study of aqueous $\mathrm{NaCl}$ solutions, a reduced dielectric constant decline at higher concentrations for some ion models was linked to excessive contact ion pairing.

The few comprehensive studies in the literature on the molecular simulation of the dielectric constant of aqueous electrolyte solutions cover only one or a few salts. No study of the dielectric constant covering a wide range of alkali halide salts in aqueous solutions, together with a comparison of several different ion force fields, has been presented to date. The main objective of this paper is thus to provide such a comprehensive comparison. The performance of eight non-polarizable ion force fields combined with the $\mathrm{TIP} 4 \mathrm{P} / \varepsilon$ water model was assessed with respect to the prediction of the dielectric constant and density of 11 aqueous alkali halide solutions ( $\mathrm{LiCl}, \mathrm{NaCl}, \mathrm{KCl}, \mathrm{RbCl}, \mathrm{CsCl}$, LiI, NaI, KI, CsI, KF, and $\mathrm{CsF}$ ). These salts were chosen as they are the only ones out of the 20 alkali halides for which reliable experimental data are available for comparison.

The present approach is as follows: first, the role of the underlying water model was investigated by comparing dielectric constant predictions for aqueous $\mathrm{NaCl}$ solutions at $298 \mathrm{~K}$ using different ion force fields together with the TIP $4 \mathrm{P} / \varepsilon$ or the SPC/E water model. As TIP $4 \mathrm{P} / \varepsilon$ yielded better predictions for all investigated ion force fields, all subsequent studies were carried out with that water model. Second, the temperature dependence of the dielectric constant was addressed again using aqueous $\mathrm{NaCl}$ solutions as an example. Third, a comprehensive assessment of eight ion force fields for the alkali halides was carried out. All 11 salts for which experimental data are available for comparison were considered. Finally, the predictions for the dielectric constant were linked to ion pairing and salt solubility in light of the ion force field parameters.

\section{METHODOLOGY}

\section{A. Molecular force fields}

Throughout this work, ions and water molecules were represented by pairwise additive, non-polarizable force fields of the LJ 12-6 type with superimposed point charges. The interaction energy between particles $i$ and $j$ is then given by

$$
u_{i j}=4 \varepsilon_{i j}\left[\left(\frac{\sigma_{i j}}{r_{i j}}\right)^{12}-\left(\frac{\sigma_{i j}}{r_{i j}}\right)^{6}\right]+\sum_{l=1}^{N_{i}^{e}} \sum_{m=1}^{N_{j}^{e}} \frac{1}{4 \pi \varepsilon_{0}} \frac{q_{l} q_{m}}{r_{l m}},
$$

where $\sigma_{i j}$ and $\varepsilon_{i j}$ are the LJ parameters for size and energy, respectively, $r_{i j}$ is the site-site distance, $q_{l}$ and $q_{m}$ are the magnitudes of point charges of the ions or water molecules separated by the distance $r_{l m}, N_{i}^{e}$ is the total number of charges of particle $i$, and $\varepsilon_{0}$ is the vacuum permittivity. All interactions between unlike $L J$ sites were specified by the Lorentz-Berthelot (LB) combining rules

$$
\begin{gathered}
\sigma_{i j}=\frac{\sigma_{i i}+\sigma_{j j}}{2}, \\
\varepsilon_{i j}=\sqrt{\varepsilon_{i i} \varepsilon_{j j}} .
\end{gathered}
$$

In most of the present simulations, water-water interactions were described with the TIP $4 \mathrm{P} / \varepsilon$ water model. ${ }^{64}$ This force field 
model is a rigid body with a single $\mathrm{LJ}$ interaction site for the oxygen atom, two positive charges for the hydrogen atoms, and one negative charge placed on a virtual site $\mathrm{M}$ on the $\mathrm{H}-\mathrm{O}-\mathrm{H}$ bisector. The force field parameters of the TIP $4 \mathrm{P} / \varepsilon$ and the SPC/E water models are given in Table S.I (supplementary material). The LJ size and energy parameters of the TIP $4 \mathrm{P} / \varepsilon$ differ only slightly from those of the TIP4P/2005 force field. TIP4P/ $\varepsilon$ was parametrized to reproduce the experimental density maximum of liquid water and the dielectric constant at ambient temperature. The significantly lower charge magnitude $q_{\mathrm{H}}=0.527 \mathrm{e}$ and virtual site offset $d_{\mathrm{OM}}=0.105 \AA$ of this model compared to TIP4P/2005 (0.5564 e, $0.1546 \AA$ ) result in an excellent coverage of the dielectric constant over a wide range of temperature and pressure. Both models give good predictions for most liquid state and vapor-liquid equilibrium properties of water.

In the present work, ions were modeled by one LJ site and a single point charge of fixed magnitude +1 e (cations) or -1 e (anions) in their center. Various ion force fields were studied, which differ by a factor of up to two for the size parameter $\sigma$ and by up to four orders of magnitude for the energy parameter $\varepsilon$, as shown in Tables S.II and S.III. A summary of parametrization properties and water models employed in the fitting procedures for the ion models is given in Table I. It should be noted that in the original works of Jensen and Jorgensen, ${ }^{35}$ Reif and Hünenberger, ${ }^{36}$ and Gee et al., ${ }^{42,43}$ geometric combination rules were employed for the unlike LJ parameters.

As none of the ion force fields studied in the present work was adjusted explicitly for the use with the TIP4P/ $\varepsilon$ water model, some remarks are given in the following about the transferability of these ion models to other water models than the ones employed in the fit. Transferability of the RDVH model parameters, fitted to reproduce the reduced liquid solution density, to four other water models was shown in the original study. ${ }^{40}$ Moreover, these model parameters were used successfully for density predictions of methanolic, ethanolic, ${ }^{74}$ and water + methanol $^{75}$ alkali halide solutions. Consistent ion force fields from Gee et al. showed similar results for various properties with different water models. Mao and Pappu developed solvent-independent force field parameters that were fitted to crystal lattice properties. ${ }^{44}$ Ion models from Joung and Cheatham parametrized with the TIP4P-Ew ${ }^{76}$ water model showed a good compatibility with the TIP4P/2005 force field for aqueous $\mathrm{NaCl}^{77}$ and $\mathrm{LiCl}^{78}$ solutions due to the similar LJ geometry and parameters of TIP4P-family models. Hence, combining different ion model sets with the TIP4P/E water model appears to be reasonable.

\section{B. Simulation details}

An extended version of the molecular simulation tool $m s 2^{79-81}$ was employed for the present calculations. Simulations of the dielectric constant and density of electrolyte solutions were performed in the isothermal-isobaric ( $N p T)$ ensemble by molecular dynamics. Eleven alkali halide brines ( $\mathrm{LiCl}, \mathrm{NaCl}, \mathrm{KCl}, \mathrm{RbCl}, \mathrm{CsCl}, \mathrm{LiI}, \mathrm{NaI}$, $\mathrm{KI}, \mathrm{CsI}, \mathrm{KF}$, and CsF) were sampled at $298 \mathrm{~K}, 1$ bar, and three concentrations for which experimental data are available, using eight different ion model sets together with TIP4P/ $\varepsilon$ water. The remaining nine alkali halide salts ( $\mathrm{LiF}, \mathrm{LiBr}, \mathrm{NaF}, \mathrm{NaBr}, \mathrm{KBr}, \mathrm{RbF}, \mathrm{RbBr}$, $\mathrm{RbI}$, and $\mathrm{CsBr}$ ) were not considered due to the lack of experimental data for comparison.

A cubic simulation volume with periodic boundary conditions contained a total of 1000 ion and solvent particles throughout. The composition of the solution is given in terms of the true ion mole fraction

$$
x_{\text {ion }}=\frac{n_{\mathrm{C}}}{2 n_{\mathrm{C}}+n_{\mathrm{W}}},
$$

where $n_{\mathrm{C}}$ and $n_{\mathrm{W}}$ are the mole numbers of cations and water, respectively. For the alkali halide brines of this study, the true ion mole fraction ranges from $0.007 \mathrm{~mol} \mathrm{~mol}^{-1}$ to $0.095 \mathrm{~mol} \mathrm{~mol}^{-1}$.

TABLE I. Summary of ion force fields considered in this work with water models used for their parametrization.

\begin{tabular}{|c|c|c|c|c|}
\hline Ion models & Abbr. & Parametrization properties & Water model & Combining rule \\
\hline Horinek et al. ${ }^{34}$ & $\mathrm{HMN}-\mathrm{S}^{\mathrm{a}}$ & Hydration free energy, hydration entropy & $\mathrm{SPC} / \mathrm{E}$ & $\ldots$ \\
\hline Fyta et al. ${ }^{38,39}$ & Fyta $^{\mathrm{b}}$ & Hydration free energy, activity derivatives & $\mathrm{SPC} / \mathrm{E}$ & LB \\
\hline Jensen-Jorgensen ${ }^{35}$ & JJ & Hydration free energy, ion-water RDF & TIP4P & Geometric \\
\hline Reif-Hünenberger ${ }^{36}$ & $\mathrm{RH}-\mathrm{L}^{\mathrm{c}}$ & Hydration free energy & $\mathrm{SPC}, \mathrm{SPC} / \mathrm{E}$ & Geometric \\
\hline Joung-Cheatham ${ }^{37}$ & $\mathrm{JC}-\mathrm{T}^{\mathrm{d}}$ & $\begin{array}{l}\text { Hydration free energy, lattice energy, lat- } \\
\text { tice constant, binding energy, ion-water } \\
\text { RDF }\end{array}$ & SPC/E, TIP3P, TIP4P-Ew & LB \\
\hline Gee et al. ${ }^{42,43}$ & $\mathrm{KBFF}$ & $\begin{array}{l}\text { Activity derivatives, ionic radii, lattice } \\
\text { constant, ion-water RDF }\end{array}$ & $\mathrm{SPC} / \mathrm{E}$ & Geometric \\
\hline Reiser et al. ${ }^{40,41}$ & RDVH & $\begin{array}{l}\text { Relative density, ion self-diffusion coeffi- } \\
\text { cient, ion-water RDF }\end{array}$ & $\mathrm{SPC} / \mathrm{E}$ & LB \\
\hline Mao-Pappu ${ }^{44}$ & MP & Lattice energy, ion-ion distance & $\ldots$ & LB \\
\hline
\end{tabular}

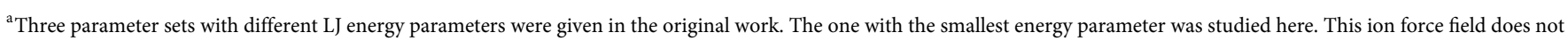
provide parameters for the $\mathrm{Rb}^{+}$cation.

${ }^{\mathrm{b}}$ This ion force field does not provide parameters for the $\mathrm{Li}^{+}$and $\mathrm{Rb}^{+}$cations. A modified $\mathrm{LB}$ combination rule was employed for cation-anion interactions in the original work. ${ }^{c}$ Three parameter sets based on different experimental hydration free energies of the proton and the SPC/E water model were given in the original work ( $\mathrm{L}_{\mathrm{E}}$, $\mathrm{M}_{\mathrm{E}}$, and $\mathrm{H}_{\mathrm{E}}$ ). The one for the lowest experimental hydration free energy $\left(\mathrm{L}_{\mathrm{E}}\right)$ was used here.

${ }^{\mathrm{d}}$ TIP4P-Ew water model specific ion parameters were used in the present work. 
The pressure was kept constant by using the Andersen barostat with a piston mass of $2.2 \times 10^{9} \mathrm{~kg} \mathrm{~m}^{-4}$. Velocity scaling was used to control the temperature. Following an equilibration of $5 \times 10^{5}$ time steps, production runs of $10^{7}$ time steps were carried out. Simulation runs over more than 5-6 ns are needed for convergence of the dielectric constant. ${ }^{24}$ Newton's equations of motion were solved with a fifth order Gear predictor-corrector scheme with a time step of $\Delta t=1.2 \mathrm{fs}$. The average runtime of a single simulation was $8 \mathrm{~h}$ on four compute nodes with 40 parallel cores per node on two Intel Xeon Gold 6148 CPU.

Electrostatic long-range contributions were calculated by Ewald summation with a real space convergence parameter $\kappa=5.6$, up to $10 k$-vectors in each Cartesian direction and conducting boundary conditions. The LJ cutoff distance and the real-space cutoff were equal with $13.8 \AA$ A.

Statistical uncertainties were estimated by means of the block averaging method by Flyvbjerg and Petersen ${ }^{82}$ with a block length of 5000 time steps. Visual snapshots of molecular configurations were recorded every 5000 time steps.

Moreover, the radial distribution function (RDF) of several salts in water $(\mathrm{NaCl}, \mathrm{KCl}, \mathrm{KI}$, and $\mathrm{LiI})$ was sampled to investigate the microscopic structure of the solutions. The number of contact ion pairs (CIP) for a 1:1 electrolyte solution can be computed from the cation-anion RDF $g_{+,-}(r)$ with

$$
n^{\mathrm{CIP}}=4 \pi \rho x_{\mathrm{ion}} \int_{0}^{r_{\min }} g_{+,-}(r) r^{2} d r
$$

where $\rho=N / V$ is the particle number density of the studied solution and $r_{\min }$ is the position of the first minimum of the cation-anion RDF.

In order to characterize the deviations between simulation results and experimental data for a given brine, the mean relative error (MRE) was calculated by

$$
\mathrm{MRE}=\frac{1}{n} \sum_{i=1}^{n} \frac{\left|z_{\text {sim }}-z_{\exp }\right|}{z_{\exp }},
$$

where $n$ is the number of data points per ion force field.

\section{Sampling of the dielectric constant}

The dielectric constant of non-polarizable fluids was computed from fluctuations ${ }^{83}$ of the total dipole moment $\mathbf{M}=\sum_{i=1}^{N} \boldsymbol{\mu}_{i}$ in the simulation volume by

$$
\varepsilon=\frac{4 \pi}{3 k_{B} T\langle V\rangle}\left(\left\langle\mathbf{M}^{2}\right\rangle-\langle\mathbf{M}\rangle^{2}\right)+1,
$$

where $k_{B}$ is the Boltzmann constant and $\boldsymbol{\mu}_{i}$ is the individual dipole moment vector of the molecule. The angled brackets denote the ensemble average.

Long simulations bring the average dipole moment $\langle\mathbf{M}\rangle$ to zero, ${ }^{25}$ as expected in the absence of an external field, ${ }^{84}$ so that the term $\langle\mathbf{M}\rangle^{2}$ in Eq. (7) vanishes.

\section{RESULTS AND DISCUSSION}

In order to evaluate the performance of the studied ion and water models with respect to dielectric constant and molar density predictions, simulations were performed as described in Sec. II for a total of 327 state points. The results of 260 simulations were compared to experimental dielectric constant and density data in Figs. 15. For the remaining simulations, indications of supersaturation or precipitation were found, as discussed further below. Tabulated numerical values of simulated properties together with their statistical uncertainties are listed in Tables S.IV-S.IX (supplementary material).

The experimental data show that with the increase of salt concentration, the dielectric constant of the solution first decreases linearly (for dilute solutions) and then non-linearly (for higher concentrations). ${ }^{85}$ This phenomenon is called dielectric decrement and is primarily explained by the reduction of orientational correlation between water molecules in the proximity of ions. ${ }^{69,86}$ It should be pointed out that some experimental data were either delivered by a single research group or may be in disagreement with other available data. Therefore, some caution regarding the reliability of these data should be taken.

The specific density of all aqueous alkali halide solutions is an increasing linear function of ion mole fraction at a given temperature. ${ }^{87}$ For many brines, the molar density shows a similar trend. Exceptions to this are the alkali iodides and $\mathrm{CsCl}$ for which the high molar mass of at least one of the ions causes the molar density to decrease with concentration.

In order to investigate the sensitivity of the ion force fields to a change of the water model, aqueous $\mathrm{NaCl}$ solutions were studied, combining each of the ion force fields with the SPC/E or with the TIP4P/ $\varepsilon$ water model. Results for the dielectric constant and the molar density under ambient conditions of temperature and pressure are shown in Fig. 1 for three salt concentrations.

The experimental dielectric constant of pure water $(\varepsilon=78.5)^{1}$ was predicted excellently with TIP4P $/ \varepsilon(\varepsilon=77.4 \pm 1.5)$, but underestimated with SPC/E $(\varepsilon=69.0 \pm 1.3)$. Both results are in good agreement with previous studies. $3,29,64$

Regarding the concentration dependence, all ion models follow the same qualitative trends for both the dielectric constant and the molar density, independent of the employed water model. The role of the water model becomes more significant when considering the quantitative agreement with experimental data. Simulations with TIP $4 \mathrm{P} / \varepsilon$ water led to a higher dielectric constant by around $8 \%$ for all ion models at the lowest concentration. This is not surprising, since water-water interactions influence the dielectric constant to a greater extent in dilute solutions and the dielectric constant of pure TIP $4 \mathrm{P} / \varepsilon$ water is higher than that of pure SPC/E water.

The HMN-S, RH-L, and JJ ion models generally led to a higher dielectric constant than other ion force fields. For more concentrated $\mathrm{NaCl}$ brines, the remaining ion models yielded an increase of up to $10 \%$ for the dielectric constant with the TIP $4 \mathrm{P} / \varepsilon$ model and were thus in better agreement with the experimental data. The molar density predictions with all ion models were quite similar for both water models.

The use of the TIP $4 \mathrm{P} / \varepsilon$ model resulted in better dielectric constant predictions for all ion force fields. These results are in line with previous findings, which suggest that 1-propanol ${ }^{88}$ and $\mathrm{NaCl}^{89}$ force fields combined with TIP4P/E water yielded dielectric constant predictions that were closer to experimental data. Thus, in the following, only TIP $4 \mathrm{P} / \varepsilon$ was considered as the water model. 

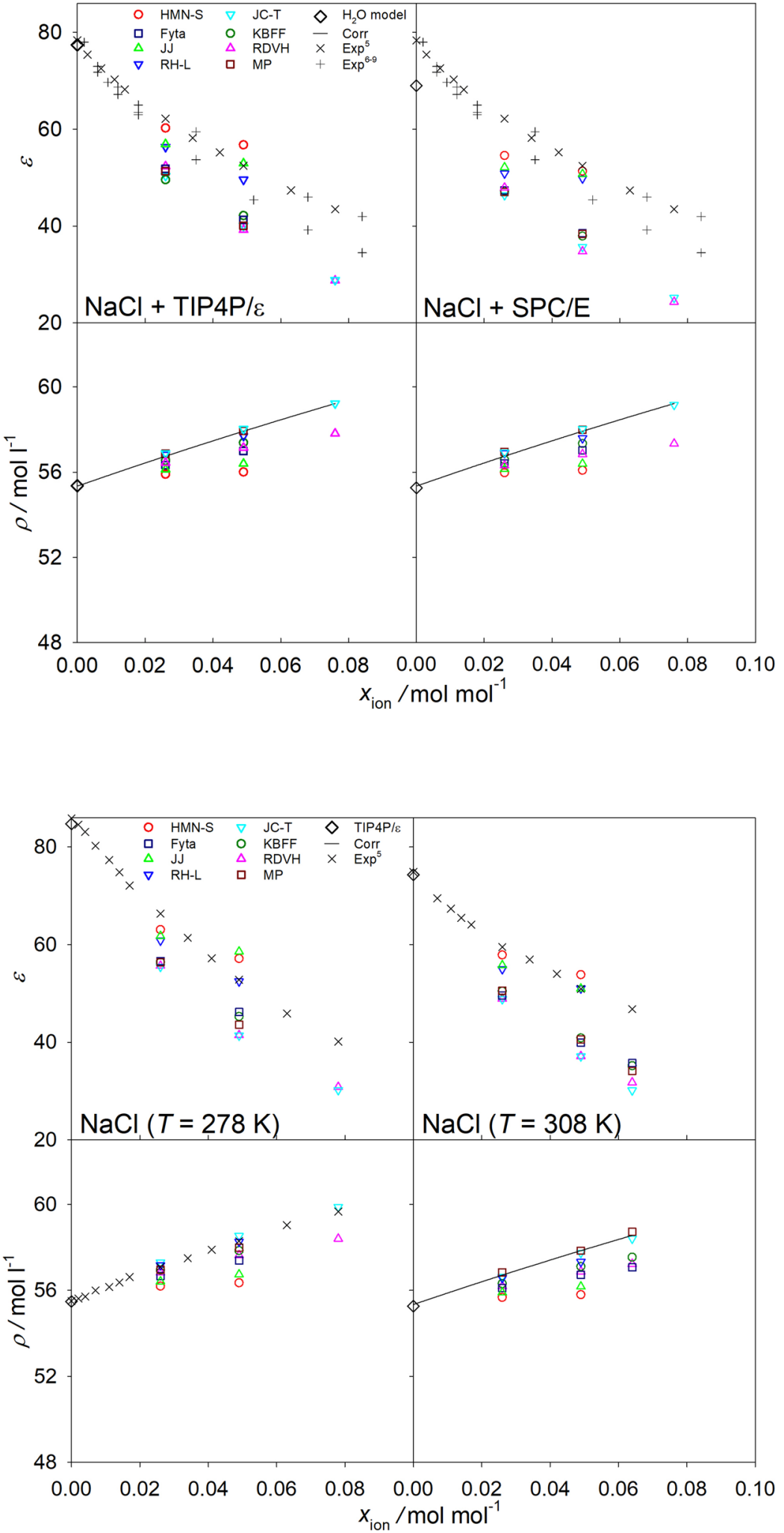

FIG. 1. Dielectric constant (top) and molar density (bottom) over true ion mole fraction of $\mathrm{NaCl}$ at $298 \mathrm{~K}$ and 1 bar. Simulation results for eight ion force fields combined with the $\mathrm{TIP} 4 \mathrm{P} / \varepsilon$ (left) and SPC/E (right) water models are represented as open colored symbols, as shown in the legend. Experimental data for comparison are represented by cross symbols. ${ }^{5}$ Other experimental data ${ }^{6-9}$ are depicted by plus symbols. The prediction for pure water is given by a diamond symbol. A correlation ${ }^{87}$ to experimental density data is shown as a black line. Statistical uncertainties are within symbol size.
FIG. 2. Dielectric constant (top) and molar density (bottom) over true ion mole fraction of $\mathrm{NaCl}$ at $278 \mathrm{~K}$ (left) and $308 \mathrm{~K}$ (right) and $1 \mathrm{bar}$. Simulation results for eight ion force fields combined with the TIP4P/ $\varepsilon$ water model are represented as open colored symbols, as shown in the legend. Experimental data for $\mathrm{NaCl}$ brine ${ }^{5}$ are represented by cross symbols. The prediction for pure water is given by a diamond symbol. A correlation ${ }^{87}$ to experimental density data is shown as a black line. Statistical uncertainties are within symbol size. 


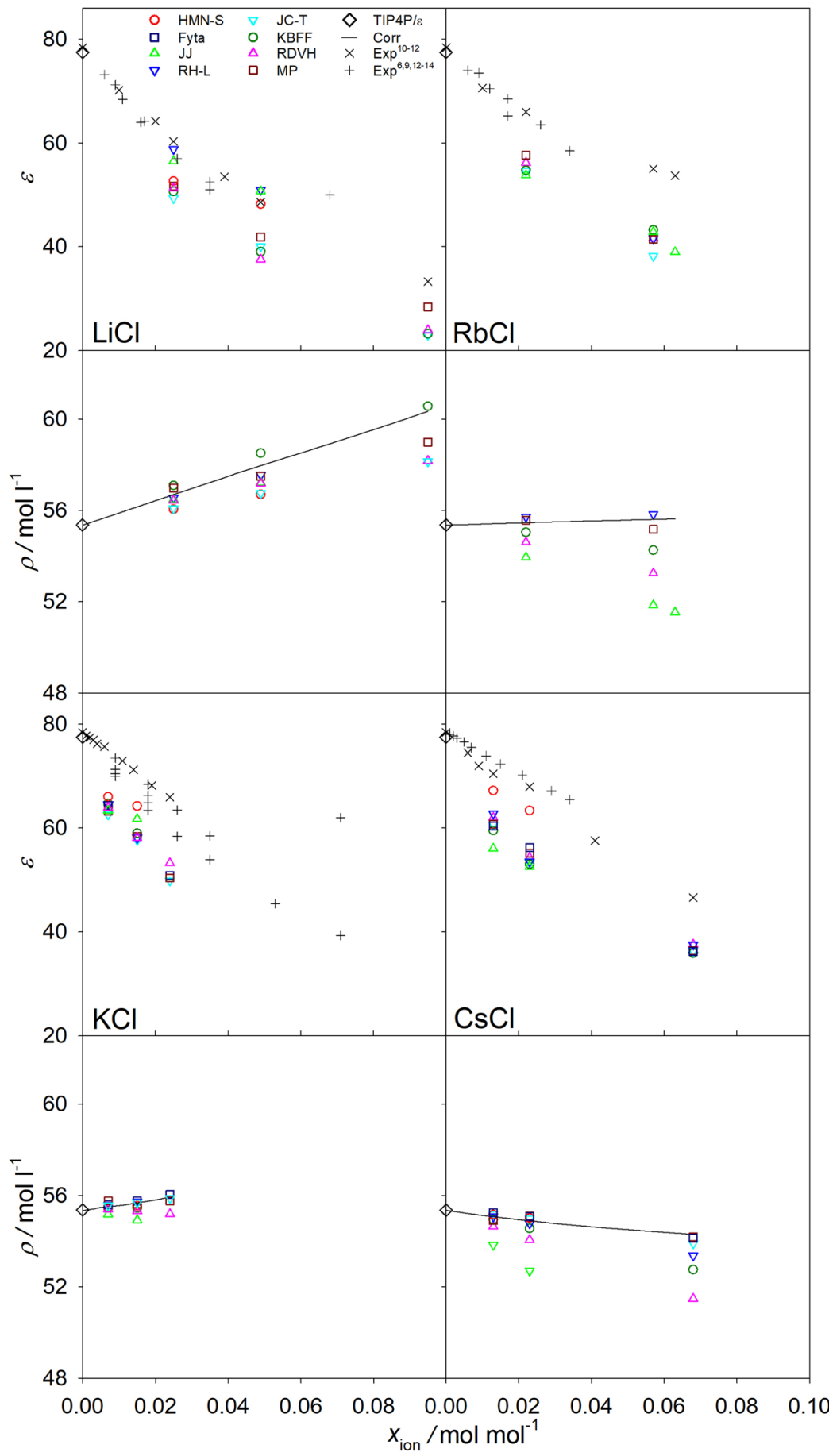

FIG. 3. Dielectric constant (top) and molar density (bottom) over true ion mole fraction of alkali chloride brines at $298 \mathrm{~K}$ and 1 bar. Simulation results for eight ion force fields combined with the TIP4P/E water model are represented as open colored symbols, as shown in the legend. Experimental data for comparison for $\mathrm{LiCl},{ }^{10} \mathrm{RbCl},{ }^{11} \mathrm{KCl},{ }^{12}$ and $\mathrm{CsCl}^{11}$ brines are represented by cross symbols. Other experimental data for $\mathrm{LiCl},{ }^{6,9,13} \mathrm{RbCl}^{9,13} \mathrm{KCl}, 6,9,13,14$ and $\mathrm{CsCl}^{12}$ brines are depicted by plus symbols. The prediction for pure water is given by a diamond symbol. A correlation ${ }^{87}$ to experimental density data is shown as a black line. Statistical uncertainties are within symbol size.

In order to check the experimentally observed decrease of the dielectric constant with the increase of temperature, $\mathrm{NaCl}$ brines were simulated for two additional temperatures $(278 \mathrm{~K}$ and $308 \mathrm{~K})$. The simulation results are compared with experimental data $^{5}$ and a correlation ${ }^{87}$ in Fig. 2. For the lower temperature, experimental density data from Ref. 5 are shown instead of a correlation.

As in Fig. 1 for aqueous $\mathrm{NaCl}$ solutions at $298 \mathrm{~K}$, the same qualitative trends were observed at $278 \mathrm{~K}$ and $308 \mathrm{~K}$ for all ion force fields. An increase of the temperature reduced the discrepancy between 


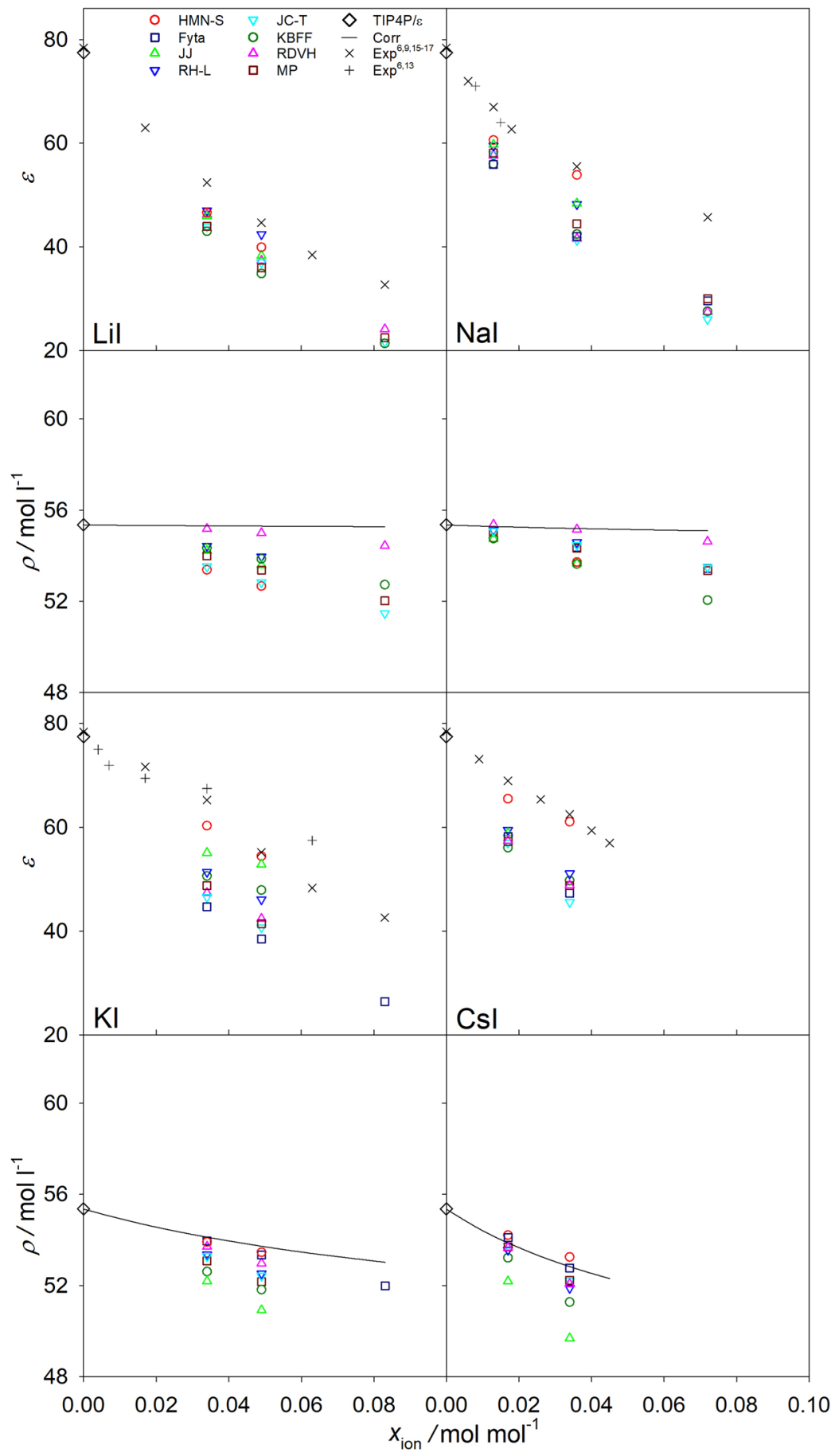

FIG. 4. Dielectric constant (top) and molar density (bottom) over true ion mole fraction of alkali iodide brines at $298 \mathrm{~K}$ and 1 bar. Simulation results for eight ion force fields combined with the $\mathrm{TIP} 4 \mathrm{P} / \varepsilon$ water model are represented as open colored symbols, as shown in the legend. Experimental data for comparison for $\mathrm{Lil}^{15}{ }^{15} \mathrm{Nal},{ }^{6,9} \mathrm{KI}^{16}$ and $\mathrm{Cs}{ }^{1}$ brines are represented by cross symbols. Other experimental data for $\mathrm{Nal}^{13}$ and $\mathrm{Kl}^{6,13}$ brines are depicted by plus symbols. The prediction for pure water is given by a diamond symbol. A correlation ${ }^{87}$ to experimental density data is shown as a black line. Statistical uncertainties are within symbol size.

simulations and experiments for the HMN-S, RH-L, and JJ force fields, but raised deviations for the remaining ion models.

The same qualitative trends were observed for the performance of the ion force fields, irrespective of the temperature or the employed water model. Thus, in the following comprehensive study of alkali halides, only the TIP4P/ $\varepsilon$ water model was used and only the temperature of $298 \mathrm{~K}$ was considered. The choice of this temperature was further motivated by the fact that for many of the investigated brines, experimental data are available only at that temperature. 


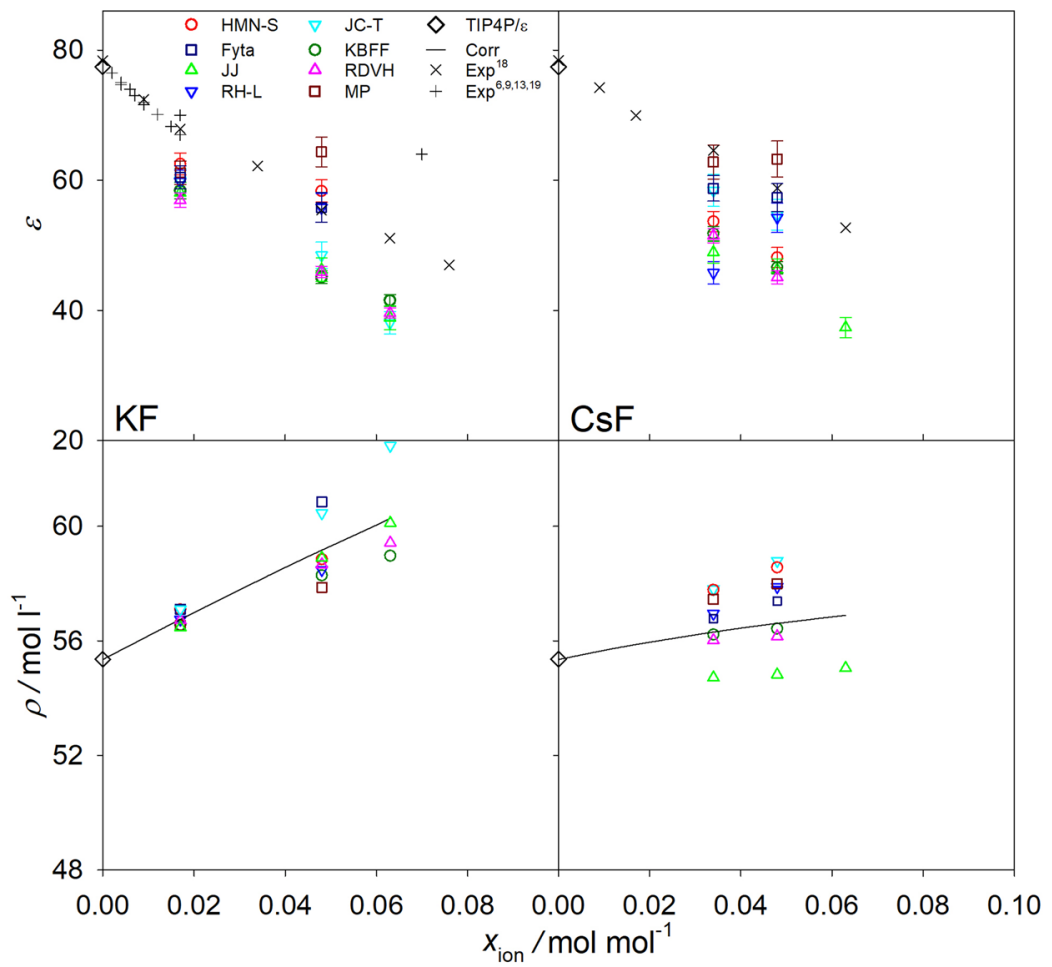

FIG. 5. Dielectric constant (top) and molar density (bottom) over true ion mole fraction of alkali fluoride brines at $298 \mathrm{~K}$ and $1 \mathrm{bar}$. Simulation results for eight ion force fields combined with the TIP4P/ $\varepsilon$ water model are represented as open colored symbols, as shown in the legend. Experimental data ${ }^{18}$ for comparison for $\mathrm{KF}$ and CsF brines are represented by cross symbols. Other experimental data for KF brine $e^{6,9,13,19}$ are depicted by plus symbols. The prediction for pure water is given by a diamond symbol. A correlation ${ }^{8}$ to experimental density data is shown as a black line. Statistical uncertainties of the molar density are within symbol size.

The results of a comprehensive study of 11 alkali halides $(\mathrm{LiCl}$, $\mathrm{NaCl}, \mathrm{KCl}, \mathrm{RbCl}, \mathrm{CsCl}$, LiI, NaI, KI, CsI, KF, and $\mathrm{CsF}$ ) in aqueous solution are presented in Figs. 3-5. The following discussion summarizes the findings obtained by comparing the performance of the ion force fields in predicting the dielectric constant and molar density of these solutions.

For nearly all considered salts, the ion force fields are able to reproduce the experimental dielectric constant and density trends at least qualitatively. However, strikingly different results regarding the slope of the dielectric constant decrement were observed for various force fields. In most cases, the dielectric constant was underpredicted in comparison to the experimental data.

The molar density, with deviations below $1.6 \%$ for almost all ion models, is in good agreement with experimental data. The HMN-S model set excellently reproduced the molar density of all potassium and cesium halide brines (except for CsF), but yielded the overall worst predictions for the remaining salts compared to the other force fields. The best overall agreement with experimental density data was obtained with the RH-L force field and the worst one with the JJ force field.

The predictions of the dielectric constant generally scatter more widely around the experimental data than those of the solution density. For the dielectric constant, at best, average deviations of $7.6 \%$ (HMN-S) and, at worst, deviations of $22.5 \%$ (JC-T) were observed. Dielectric constant calculations with $\mathrm{HMN}-\mathrm{S}$ were superior to other models for all studied salts. The best representation of the dielectric constant of $\mathrm{NaCl}$ brines at all temperatures was given by the $\mathrm{RH}-\mathrm{L}+\mathrm{TIP} 4 \mathrm{P} / \varepsilon$ model combination. The worst agreement for the dielectric constant, with discrepancies to experiments of at least $20 \%$, was found for the KBFF, RDVH, and JC-T force fields. An overview of the deviations between the simulation and experiment is provided in Table II.

In general, low concentration simulations gave better predictions for dielectric constant and molar density, which is not surprising as the water-water interactions dominate the solution behavior. By contrast, the dielectric constant of $\mathrm{KCl}$ brine, calculated only up to $0.024 \mathrm{~mol} \mathrm{~mol}^{-1}$ (as no reliable data for the dielectric constant are available at higher concentrations), was in poor agreement with experimental data.

Qualitative disagreement with experimental dielectric constant data, as well as over- and underestimation of density data, was found for some alkali fluoride models (cf. Fig. 5). Taking into account that difficulties in modeling alkali fluorides, especially regarding the solubility, have been reported in the literature, ${ }^{37-39,50}$ we suggest that results for these brines should be analyzed with care.

Interestingly, the models that performed overall best for the dielectric constant (HMN-S, RH-L, and JJ), in general, led to higher values for the dielectric constant compared to the other models. In some cases, these ion force fields even overestimated the experimental dielectric constant for more concentrated chloride brines, e.g., $\mathrm{NaCl}$ or LiCl. Predictions higher than the experimental dielectric constant were also found for those model sets in the case of aqueous $\mathrm{LiCl}$ before.

Some of the models yielded much higher predictions of the dielectric constant than others, especially for more concentrated brines. In order to find a possible explanation, the cation-anion RDF 
TABLE II. Mean relative error (MRE) between simulation data and experimental results for the dielectric constant and molar density of 11 alkali halide brines studied with different ion force fields. All simulations were carried out with the TIP4P/E water model and at $298 \mathrm{~K}$, except where noted otherwise.

\begin{tabular}{|c|c|c|c|c|c|c|c|c|}
\hline \multicolumn{9}{|c|}{$100 \operatorname{MRE}(\varepsilon)$} \\
\hline Model & HMN-S & Fyta & JJ & RH-L & JC-T & $\mathrm{KBFF}$ & RDVH & MP \\
\hline \multicolumn{9}{|l|}{ Salt } \\
\hline $\mathrm{NaCl}$ & 5.7 & 18.9 & 4.7 & 6.1 & 26.8 & 19.9 & 24.9 & 20.5 \\
\hline $\mathrm{NaCl}(\mathrm{SPC} / \mathrm{E})$ & 7.2 & 25.1 & 9.7 & 11.6 & 33.1 & 25.8 & 33.5 & 25.5 \\
\hline $\mathrm{NaCl}(278 \mathrm{~K})$ & 6.6 & 13.6 & 8.9 & 4.5 & 20.9 & 14.6 & 20.2 & 16.2 \\
\hline $\mathrm{NaCl}(308 \mathrm{~K})$ & 4.2 & 20.6 & 3.2 & 3.9 & 26.9 & 19.9 & 25.7 & 20.8 \\
\hline $\mathrm{LiCl}$ & 6.7 & & 5.3 & 3.7 & 22.2 & 22.0 & 22.0 & 14.3 \\
\hline $\mathrm{RbCl}$ & & & 22.7 & 24.2 & 15.9 & 12.8 & 13.0 & 12.4 \\
\hline $\mathrm{KCl}$ & 11.8 & 19.5 & 15.3 & 17.0 & 21.0 & 16.4 & 18.5 & 20.2 \\
\hline $\mathrm{CsCl}$ & 6.7 & 23.4 & 27.3 & 22.9 & 24.7 & 25.7 & 22.9 & 23.8 \\
\hline LiI & 10.9 & & 13.3 & 7.7 & 22.4 & 24.9 & 18.1 & 22.3 \\
\hline $\mathrm{NaI}$ & 6.3 & 25.4 & 11.8 & 12.2 & 27.4 & 26.6 & 26.3 & 22.5 \\
\hline KI & 4.5 & 33.3 & 9.9 & 18.9 & 27.5 & 17.8 & 25.3 & 25.1 \\
\hline CsI & 3.7 & 12.9 & 18.2 & 16.1 & 21.9 & 19.5 & 19.3 & 19.5 \\
\hline KF & 6.6 & 5.9 & 18.3 & 6.3 & 16.5 & 17.1 & 18.6 & 7.7 \\
\hline $\mathrm{CsF}$ & 17.5 & 5.8 & 24.9 & 18.4 & 8.3 & 20.3 & 21.8 & 5.2 \\
\hline Average & 7.6 & 18.6 & 13.8 & 12.4 & 22.5 & 20.2 & 22.2 & 18.3 \\
\hline \multicolumn{9}{|c|}{$100 \operatorname{MRE}(\rho)$} \\
\hline $\mathrm{NaCl}$ & 2.3 & 1.1 & 1.8 & 0.3 & 0.2 & 0.6 & 1.3 & 0.2 \\
\hline $\mathrm{NaCl}(\mathrm{SPC} / \mathrm{E})$ & 2.2 & 1.0 & 1.8 & 0.4 & 0.2 & 0.6 & 1.8 & 0.3 \\
\hline $\mathrm{NaCl}(278 \mathrm{~K})$ & 1.6 & 0.8 & 1.3 & 0.1 & 0.4 & 0.3 & 1.2 & 0.2 \\
\hline $\mathrm{NaCl}(308 \mathrm{~K})$ & 1.6 & 1.5 & 1.2 & 0.2 & 0.2 & 0.9 & 1.2 & 0.6 \\
\hline $\mathrm{LiCl}$ & 1.7 & & 0.8 & 0.5 & 2.3 & 0.7 & 1.8 & 1.2 \\
\hline $\mathrm{RbCl}$ & & & 5.6 & 0.4 & 0.3 & 1.6 & 2.9 & 0.5 \\
\hline $\mathrm{KCl}$ & 0.1 & 0.4 & 1.0 & 0.1 & 0.1 & 0.2 & 0.7 & 0.3 \\
\hline $\mathrm{CsCl}$ & 0.2 & 0.3 & 5.7 & 0.6 & 0.4 & 1.2 & 2.5 & 0.3 \\
\hline LiI & 4.1 & & 2.5 & 2.0 & 4.9 & 3.0 & 0.8 & 3.9 \\
\hline $\mathrm{NaI}$ & 1.8 & 1.7 & 1.9 & 0.7 & 1.5 & 3.1 & 0.4 & 1.7 \\
\hline KI & 0.4 & 1.0 & 4.4 & 1.8 & 2.0 & 3.2 & 1.1 & 2.4 \\
\hline CsI & 0.7 & 0.5 & 4.5 & 1.2 & 0.7 & 2.1 & 0.9 & 0.7 \\
\hline $\mathrm{KF}$ & 0.6 & 1.7 & 0.4 & 0.6 & 2.3 & 1.3 & 0.8 & 1.2 \\
\hline CsF & 3.0 & 1.1 & 3.1 & 1.7 & 3.3 & 0.2 & 0.6 & 2.5 \\
\hline Average & 1.6 & 1.0 & 2.6 & 0.8 & 1.3 & 1.4 & 1.3 & 1.1 \\
\hline
\end{tabular}

$g_{+,-}(r)$ of four electrolyte solutions $(\mathrm{NaCl}, \mathrm{KCl}, \mathrm{KI}$, and $\mathrm{LiI})$ was sampled, as shown in Fig. 6.

Positions and magnitudes of the first RDF maximum, corresponding to the contact distance and likelihood of contact ion pairs, respectively, differ significantly between various model sets. The lowest contact distances were observed for the HMN-S and JC-T models and the highest for the JJ and RDVH models. Positions of the first RDF maximum shift to larger distances with the increase of cation or anion size.

Very high first peaks, suggesting excessive ion pairing, were formed by the HMN-S model set for the studied salt solutions in
Fig. 6. In addition, the ordered oscillating behavior of subsequent peaks obtained with this model set (except for LiI) indicates crystal formation in the aqueous solution below the experimental solubility limit. Pronounced oscillations of the RDF curves, which suggest crystallization, were also observed in the case of the RH-L and JJ models for $\mathrm{NaCl}$, as well as for the $\mathrm{KBFF}$ and $\mathrm{JJ}$ models for $\mathrm{KI}$. Models that have the lowest first peaks for $\mathrm{NaCl}$, i.e., JC- $\mathrm{T}$ and RDVH, accompanied by MP and KBFF for LiI, gave a higher second than first RDF maximum, which corresponds to a higher likelihood of solvent-shared ion pairs (SIP) than CIP. In SIP, a single solvent shell separates the partner ions, while in CIP, there are 


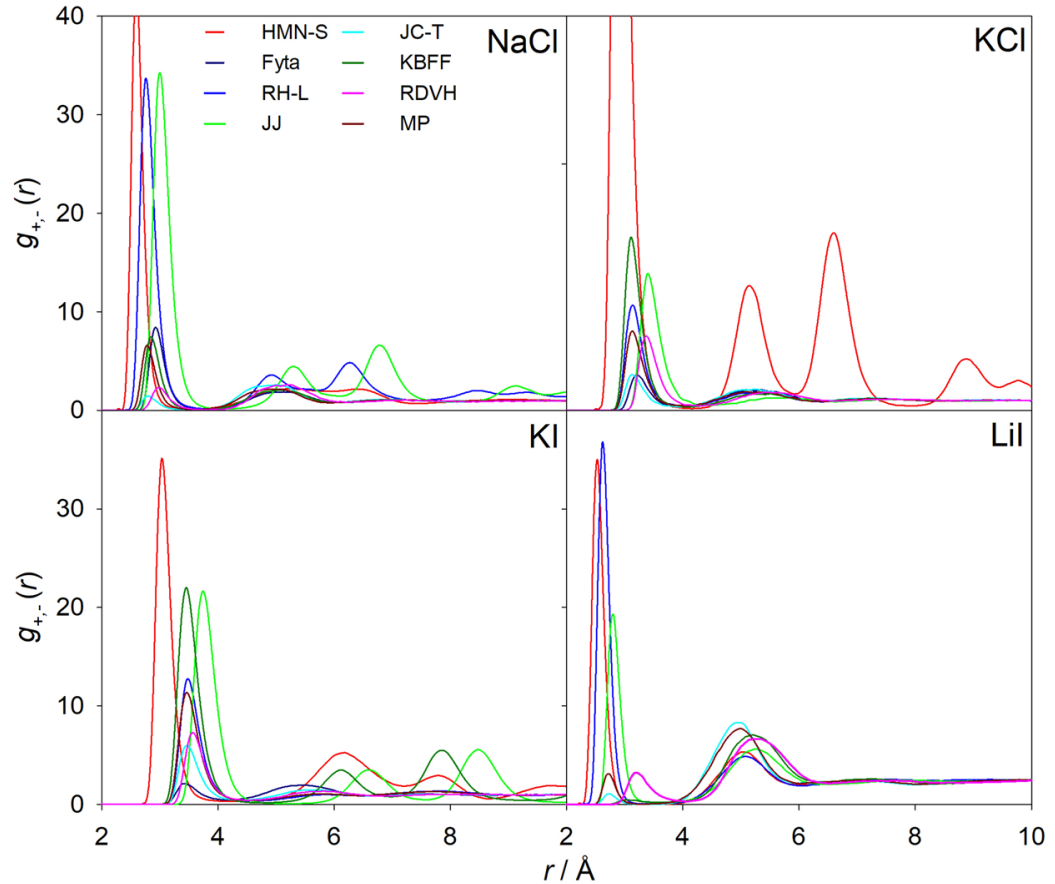

FIG. 6. Cation-anion radial distribution function over the distance of aqueous $\mathrm{NaCl}\left(0.076 \mathrm{~mol} \mathrm{~mol}^{-1}\right), \mathrm{KCl}(0.024$ $\left.\mathrm{mol} \mathrm{mol}^{-1}\right), \mathrm{KI}\left(0.083 \mathrm{~mol} \mathrm{~mol}^{-1}\right)$, and Lil $(0.083 \mathrm{~mol}$ $\mathrm{mol}^{-1}$ ) solutions at $298 \mathrm{~K}$ and 1 bar. Simulation results for eight ion force fields combined with the $\mathrm{TIP} 4 \mathrm{P} / \varepsilon$ water model are represented by colored lines, as shown in the legend. no solvent molecules between the cations and anions. ${ }^{4}$ In nearly all other cases, higher first peaks were followed by lower subsequent peaks, as expected for a solution of a completely dissociated salt.
The magnitude of the RDF maximum can provide a relationship with the over- and underestimation of the dielectric constant for a given ion model. In order to establish a connection between the present predictions and excessive ion pairing and

TABLE III. Number of contact ion pairs $n^{\mathrm{CIP}}$ calculated from the cation-anion RDF of each brine and each ion force field at $298 \mathrm{~K}, 1 \mathrm{bar}$, and the highest investigated concentration. The asterisk indicates a supersaturated solution $\left(n^{\mathrm{ClP}}>0.5\right)$ according to the ionic pairs rule of Benavides et al., ${ }^{52}$ which can be employed for brines with a model solubility limit below $10 \mathrm{~mol} \mathrm{~kg}^{-1}$. Brines with an experimental solubility limit above $10 \mathrm{~mol} \mathrm{~kg}^{-1}$ are listed below the horizontal line. For these brines, supersaturated solutions indicated by an asterisk were observed in the snapshots of the final configuration for the investigated model combination.

\begin{tabular}{lcccccccc}
\hline \hline Model & HMN-S & Fyta & JJ & RH-L & JC-T & KBFF & RDVH & MP \\
\hline Salt & & & & & & & & \\
$\mathrm{NaCl}$ & $2.97^{*}$ & $0.84^{*}$ & $3.74^{*}$ & $2.97^{*}$ & 0.14 & $0.69^{*}$ & 0.28 & $0.57^{*}$ \\
$\mathrm{NaCl}(\mathrm{SPC} / \mathrm{E})$ & $2.85^{*}$ & $0.85^{*}$ & $3.69^{*}$ & $2.97^{*}$ & 0.15 & $0.66^{*}$ & 0.26 & $0.57^{*}$ \\
$\mathrm{NaCl}(278 \mathrm{~K})$ & $2.69^{*}$ & $0.78^{*}$ & $3.25^{*}$ & $2.23^{*}$ & 0.10 & $0.62^{*}$ & 0.27 & $0.52^{*}$ \\
$\mathrm{NaCl}(308 \mathrm{~K})$ & $1.13^{*}$ & 0.11 & $1.42^{*}$ & $1.57^{*}$ & 0.09 & 0.12 & 0.24 & 0.39 \\
$\mathrm{RbCl}$ & & & 0.20 & $0.74^{*}$ & $0.52^{*}$ & $1.61^{*}$ & $1.28^{*}$ & $0.69^{*}$ \\
$\mathrm{KCl}$ & $3.78^{*}$ & 0.22 & $0.90^{*}$ & $0.55^{*}$ & 0.21 & $0.80^{*}$ & 0.49 & 0.43 \\
$\mathrm{KI}$ & $3.61^{*}$ & 0.45 & $4.38^{*}$ & $2.33^{*}$ & $1.16^{*}$ & $3.82^{*}$ & $1.46^{*}$ & $2.10^{*}$ \\
$\mathrm{CsI}$ & $4.30^{*}$ & $0.91^{*}$ & $2.43^{*}$ & $0.70^{*}$ & $0.97^{*}$ & $1.24^{*}$ & $1.36^{*}$ & $0.98^{*}$ \\
$\mathrm{CsF}$ & $1.63^{*}$ & $2.20^{*}$ & 0.01 & $1.63^{*}$ & $0.86^{*}$ & $0.57^{*}$ & $0.83^{*}$ & $1.90^{*}$ \\
\hline $\mathrm{LiCl}$ & $1.36^{*}$ & & $1.66^{*}$ & $1.81^{*}$ & 0.32 & 0.27 & 0.48 & 0.64 \\
$\mathrm{CsCl}$ & $4.26^{*}$ & 1.09 & $1.59^{*}$ & 1.18 & 0.94 & 0.20 & 1.57 & 0.86 \\
$\mathrm{LiI}$ & $0.75^{*}$ & & $0.56^{*}$ & $0.85^{*}$ & 0.03 & 0.04 & 0.25 & 0.08 \\
$\mathrm{NaI}$ & $2.65^{*}$ & 0.51 & $2.00^{*}$ & $1.44^{*}$ & 0.15 & 0.21 & 0.19 & 0.48 \\
$\mathrm{KF}$ & $3.10^{*}$ & $1.40^{*}$ & 0.14 & $2.71^{*}$ & 0.61 & 0.71 & 0.73 & $3.58^{*}$ \\
\hline \hline
\end{tabular}


solubility, the number of contact ion pairs $n^{\mathrm{CIP}}$ was calculated from the cation-anion RDF according to Eq. (5), as listed in Table III.

Based on the number of contact ion pairs, the solubility of 1:1 electrolytes in water may be roughly estimated with the ionic pairs rule proposed by Benavides et al. ${ }^{52}$ For salts with a model solubility limit below $10 \mathrm{~mol} \mathrm{~kg}{ }^{-1}, n^{\mathrm{CIP}}>0.5$ is an indicator for a supersaturated solution, i.e., the solubility of the model is lower than the currently investigated concentration. The rule of Benavides et al. is, however, not applicable for salts with a model solubility limit larger than $10 \mathrm{~mol} \mathrm{~kg}^{-1}$. Salts with an experimental solubility limit above $10 \mathrm{~mol} \mathrm{~kg}^{-1}$, such as $\mathrm{LiCl}, \mathrm{CsCl}$, LiI, NaI, and KF, were thus not treated by the ionic pairs rule. Instead, for these brines, we looked at the snapshot of the final sampled configuration to check visually whether the solution was supersaturated or crystals were formed. All brines and ion force fields studied in this manner at the highest concentration are listed in Table III.

Models with $n^{\mathrm{CIP}}>0.5$ predict a higher dielectric constant than models with $n^{\mathrm{CIP}}<0.5$, as less water molecules are needed to form hydration shells, and thus, the remaining ones can orient freely.

If crystallization was clearly indicated, as in Fig. 6 and Table III for the $\mathrm{NaCl}$ models HMN-S, RH-L, and JJ, the increase of the dielectric constant was more pronounced. In other words, the reduced model solubility causes premature precipitation, which in turn increases the dielectric constant. Striking differences for the solution structure of a $\mathrm{NaCl}$ brine are displayed by snapshots of the microscopic configurations in Fig. 7. We also prepared snapshots of the final configuration of each investigated model combination. The visual impression that they provide was always consistent with the rule of Benavides et al. Due to the large number of state points, we refrained from including all these snapshots here or in the supplementary material.

To obtain a compact overview of the connection between the prediction for the dielectric constant and the number of contact ion pairs, $\varepsilon$ is shown as a function of $n^{\text {CIP }}$ for each brine and each ion force field at the highest investigated concentration in Figs. 8 and 9.

For most brines, a clear trend is visible in Figs. 8 and 9: points are either found in the lower left or in the upper right part of the plot. This means that all ion force fields that yielded a comparably high dielectric constant at high concentrations were well beyond their solubility limit. The models that did not show this premature precipitation behavior also always predicted a lower dielectric constant.

Hence, a higher number of contact ion pairs caused an increase of the dielectric constant and thus led to a seemingly better quantitative agreement with experimental data. The argument of a recent study by Seal et al. ${ }^{72}$ that stronger ion pairing leads to a reduced dielectric constant decline at higher $\mathrm{NaCl}$ concentrations is thus confirmed here. Another study of the dielectric spectra of $\mathrm{NaCl}$ solutions using the GROMOS ${ }^{90}$ force field also found an increment of the dielectric constant due to excessive ion pairing.

Table III clearly indicates that most of the ion force fields showed premature precipitation for many of the studied brines. Precipitation falsifies results not only for the dielectric constant but also for any other thermodynamic property. Exceptions were the JC-T and RDVH force fields for which only four of the investigated brines were probably above the solubility limit. In fact,
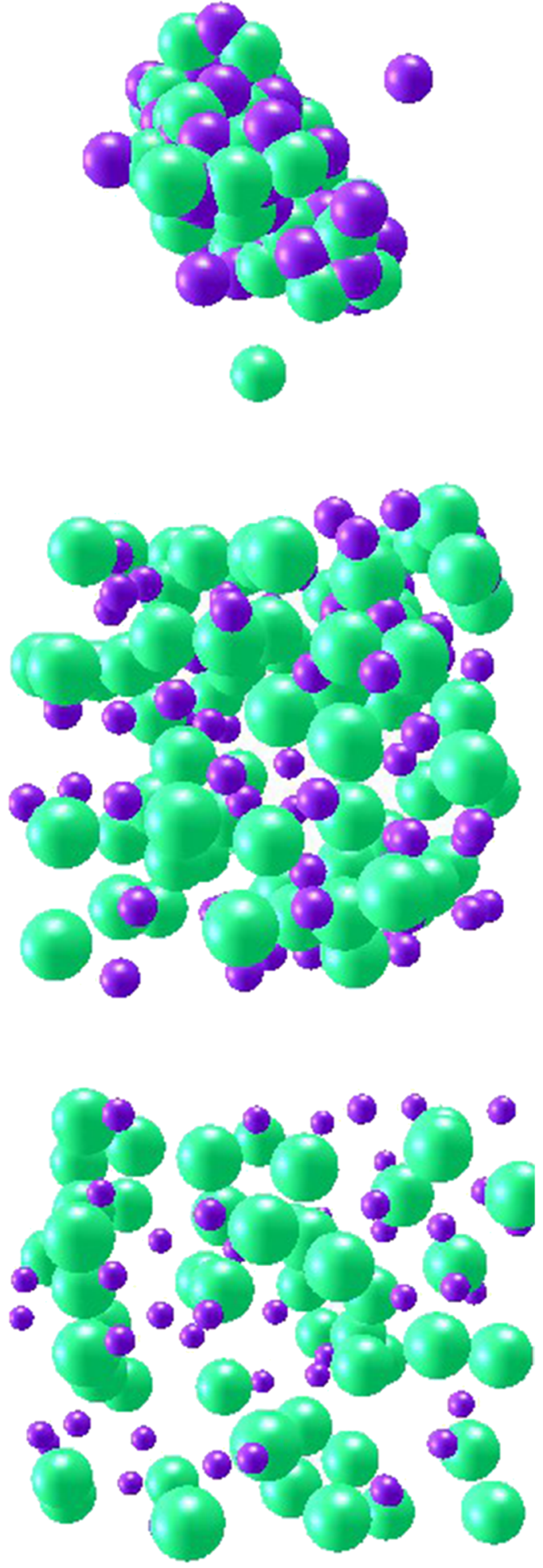

FIG. 7. Snapshots of $\mathrm{NaCl}$ configurations modeled by HMN-S (top), MP (center), and RDVH (bottom) force fields in TIP4P/ $\varepsilon$ water at $298 \mathrm{~K}, 1$ bar, and $0.076 \mathrm{~mol} \mathrm{~mol}^{-1}$. Violet and green spheres represent $\mathrm{Na}^{+}$and $\mathrm{Cl}^{-}$, respectively. Water particles are left out for clarity. 


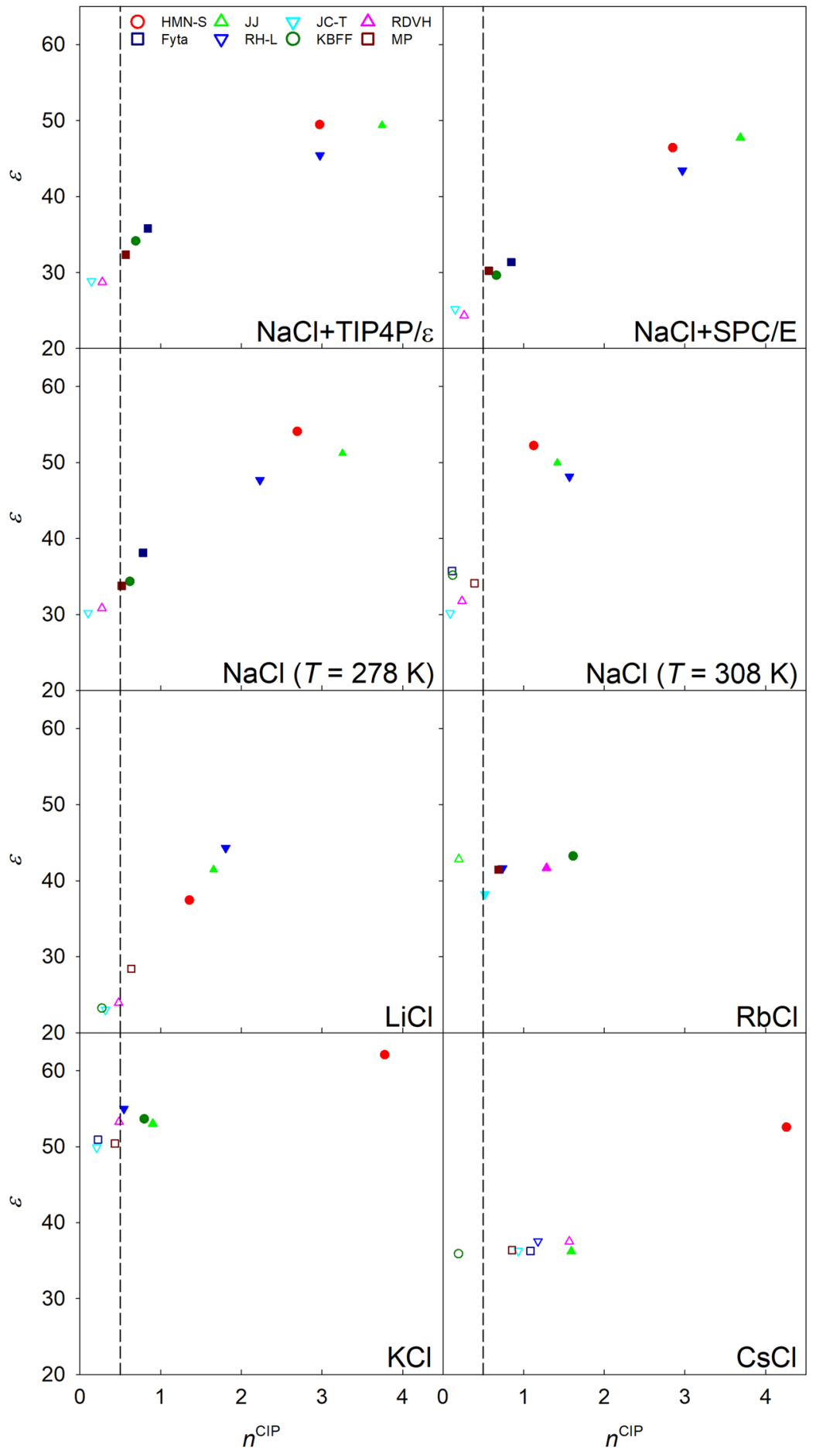

FIG. 8. Dielectric constant as a function of the number of contact ion pairs for alkali chloride brines at the highest investigated concentration. Solid symbols indicate that the solution was likely supersaturated or premature crystallization was observed. The dashed vertical line at $n^{\mathrm{CIP}}=0.5$ indicates the limit beyond which this is likely to occur according to the rule of Benavides et al. ${ }^{52}$

Moucka et al. ${ }^{46}$ tested the solubility of 13 force fields for $\mathrm{NaCl}$ brine with SPC/E water, among them all ion force fields of this study, except for JJ and MP. They also found that only two ion model sets (JC-SPC/E and HMN-M) did not show premature precipitation.
The seemingly good reproduction of both the dielectric constant and molar density with some ion models is, therefore, probably associated with premature crystallization. Hence, it may be only a coincidence of an unphysical behavior of the respective model, which is thus not useful. 


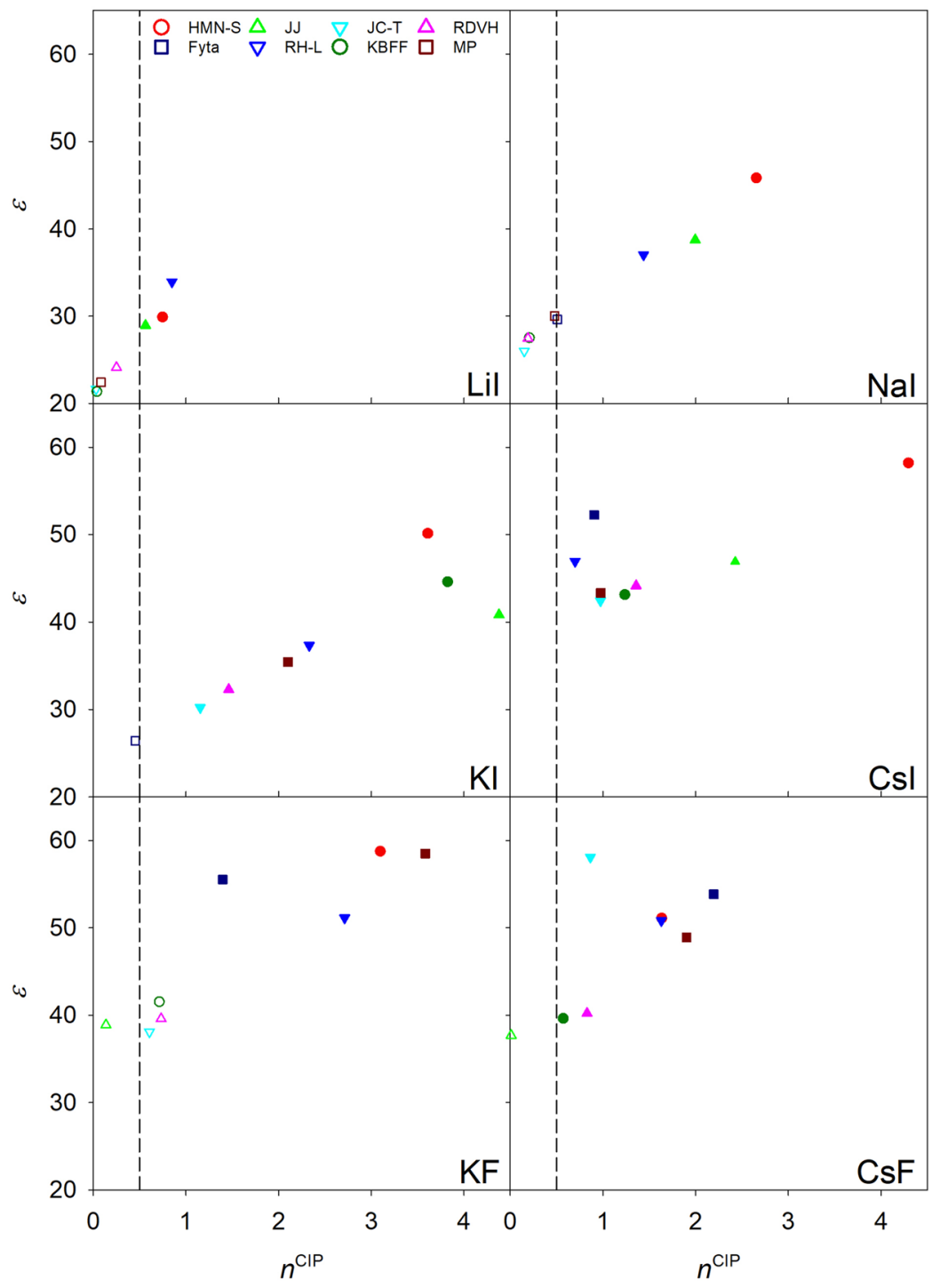

FIG. 9. Dielectric constant as a function of the number of contact ion pairs for alkali iodide and fluoride brines at the highest investigated concentration. Solid symbols indicate that the solution was likely supersaturated or premature crystallization was observed. The dashed vertical line at $n^{\mathrm{CIP}}=0.5$ indicates the limit beyond which this is likely to occur according to the rule of Benavides et al. ${ }^{52}$

The increase of the dielectric constant with strong ion pairing is contrary to the expected existence of real ion pair species in strong 1:1 electrolyte solutions. The dielectric constant has to be very low $(\varepsilon<30)$ under ambient conditions for uni-univalent ion pairs to be formed. ${ }^{4}$ In fact, the strong drop of the sampled dielectric constant of aqueous $\mathrm{NaCl}$ observed before at higher temperatures was the cause of enhanced ion pairing. ${ }^{92}$

Since strong attraction of cation and anion in solution initiates excessive contact ion pairing, causes for the specific dielectric constant behavior of some models may eventually lie in unbalanced force field parameters. In general, similarly sized ions (small-small and large-large) favor ion association in water, while a combination of small and large ions readily dissociates. $^{93-95}$ In addition to that is the counterintuitive behavior of the LJ energy parameter for ions in water, for which lower values lead to a softer repulsion and stronger electrostatic attraction. ${ }^{41,9}$

Since all repulsive and dispersive interactions were described in this study with $12 \mathrm{LJ}$ parameters for like and unlike ion and water interactions, it is not straightforward to establish a clear connection between the LJ parameters and the present results. However, in order to relate the findings of this study to the force field parameters of the ions, the ratio between the cation and anion LJ size and energy parameters for each force field is listed in Table S.X.

Ion models that predicted a high dielectric constant, such as HMN-S, had generally similar cation and anion sizes and low LJ energy parameters. On the other hand, ion models with higher LJ energies and strong deviations to the size ratio of unity, such as JC-T, gave a lower number of contact ion pairs. Low 
LJ cation diameters of the JC-T models are an indication for an increased model solubility ${ }^{96}$ and stronger ion solvation ${ }^{34}$ in water.

\section{CONCLUSIONS}

Eleven aqueous alkali halide solutions were studied with respect to the concentration dependence of the dielectric constant and molar density under ambient conditions by molecular simulation. For that purpose, eight non-polarizable force fields for the ions and the $\mathrm{TIP} 4 \mathrm{P} / \varepsilon$ model for water were employed.

Almost all ion force fields predicted a decrease of the dielectric constant with the increase of salt concentration for the considered electrolyte solutions. The quantitative agreement with experimental data was poor in many cases. However, the drop of the dielectric constant with the increase of temperature was confirmed for $\mathrm{NaCl}$ brine. The solution density was predicted well with most ion models. The TIP4P/ $\varepsilon$ water model somewhat improved the predictions of the ion force fields regarding the dielectric constant compared to SPC/E.

The key finding of this study is that the generally higher dielectric constant predictions of some ion models are associated with excessive ion pairing and/or premature crystallization. This may explain the seemingly good dielectric constant and density agreement with experiments for those models or, in some cases, the overestimation of the experimental dielectric constant. The cause probably lies in unbalanced force field parameters and hence the reduced model solubility. These findings are contrary to the expected formation of ion pairs with a strong drop of the dielectric constant for 1:1 electrolyte solutions under ambient conditions.

It is clear that further investigations of the dielectric constant of aqueous electrolyte solutions require ion models predicting solubilities close to experimental ones. For example, the recently proposed Madrid-2019 force fields ${ }^{97,98}$ with scaled charges showed good solubility predictions. Reduced charges were used in the excellent reproduction of the experimental dielectric constant for $\mathrm{NaCl}, \mathrm{NaBr}, \mathrm{KCl}$, and $\mathrm{KBr}$ solutions ${ }^{89,99}$ with the TIP4P/E water model. However, these findings were compromised with poor solubility and activity predictions of the $\mathrm{NaCl} / \varepsilon+\mathrm{TIP} 4 \mathrm{P} / \varepsilon$ combination. ${ }^{100}$ In light of the present conclusions, questions arise whether an ion parametrization to the dielectric constant makes sense without an adequate reproduction of the experimental solubility limit.

\section{SUPPLEMENTARY MATERIAL}

See the supplementary material for tabulated numerical simulation values and force field parameters used for the water and ion models in this study.

\section{ACKNOWLEDGMENTS}

We gratefully acknowledge the Paderborn Center for Parallel Computing $\left(\mathrm{PC}^{2}\right)$ for the generous allocation of computer time on the OCuLUS and Noctua clusters. D.S. gratefully acknowledges the support by the Konrad-Adenauer-Stiftung e.V.

\section{REFERENCES}

${ }^{1}$ M. Uematsu and E. U. Frank, J. Phys. Chem. Ref. Data 9, 1291 (1980).

${ }^{2}$ D. C. Elton, "Understanding the dielectric properties of water," Ph.D. thesis, State University of New York at Stony Brook, 2016.

${ }^{3}$ G. Raabe and R. J. Sadus, J. Chem. Phys. 134, 234501 (2011).

${ }^{4}$ Y. Marcus and G. Hefter, Chem. Rev. 106, 4585 (2006).

${ }^{5}$ R. Buchner, G. T. Hefter, and P. M. May, J. Phys. Chem. A 103, 1 (1999).

${ }^{6}$ F. E. Harris and C. T. O’Konski, J. Phys. Chem. 61, 310 (1957).

${ }^{7}$ V. V. Shcherbakov, Y. M. Artemkina, and E. N. Korotkova, Russ. J. Inorg. Chem. 59, 922 (2014).

${ }^{8}$ J. B. Hasted and G. W. Roderick, J. Chem. Phys. 29, 17 (1958).

${ }^{9}$ G. H. Haggis, J. B. Hasted, and T. J. Buchanan, J. Chem. Phys. 20, 1452 (1952).

${ }^{10}$ Y.-Z. Wei and S. Sridhar, J. Chem. Phys. 92, 923 (1990).

${ }^{11}$ Y.-Z. Wei, P. Chiang, and S. Sridhar, J. Chem. Phys. 96, 4569 (1992).

${ }^{12}$ T. Chen, G. Hefter, and R. Buchner, J. Phys. Chem, A 107, 4025 (2003).

${ }^{13}$ J. B. Hasted, D. M. Ritson, and C. H. Collie, J. Chem. Phys. 16, 1 (1948).

${ }^{14} \mathrm{~J}$. Liszi, A. Felinger, and E. H. Kristóf, Electrochim. Acta 33, 1191 (1988).

${ }^{15}$ A. K. Lyashchenko, A. V. Kobelev, I. M. Karataeva, and A. S. Lileev, Russ. J. Inorg. Chem. 59, 757 (2014).

${ }^{16}$ A. V. Kobelev, A. S. Lileev, and A. K. Lyashchenko, Russ. J. Inorg. Chem. 56, $652(2011)$

${ }^{17}$ A. V. Kobelev, A. S. Lileev, and A. K. Lyashchenko, Russ. J. Inorg. Chem. 56, 1666 (2011).

${ }^{18}$ D. V. Loginova, A. S. Lileev, and A. K. Lyashchenko, Russ. J. Phys. Chem. A 80, 1626 (2006).

${ }^{19}$ R. Buchner, G. T. Hefter, and J. Barthel, J. Chem. Soc., Faraday Trans. 90, 2475 (1994).

${ }^{20}$ J. B. Hubbard, P. Colonomos, and P. G. Wolynes, J. Chem. Phys. 71, 2652 (1979).

${ }^{21}$ R. Buchner and J. Barthel, Annu. Rep. Prog. Chem. 97, 349 (2001).

${ }^{22}$ I. Y. Shilov and A. K. Lyashchenko, J. Phys. Chem. B 119, 10087 (2015).

${ }^{23}$ A. Lyashchenko and A. Lileev, J. Chem. Eng. Data 55, 2008 (2010).

${ }^{24}$ O. Gereben and L. Pusztai, Chem. Phys. Lett. 507, 80 (2011).

${ }^{25}$ E. Galicia-Andrés, H. Dominguez, and O. Pizio, Condens. Matter Phys. 18, 13603 (2015).

${ }^{26}$ M. Kohns, Fluid Phase Equilib. 506, 112393 (2020).

${ }^{27}$ E. Wasserman, B. Wood, and J. Brodhol, Geochim. Cosmochim. Acta 59, 1 (1995).

${ }^{28}$ L. Fumagalli, A. Esfandiar, R. Fabregas, S. Hu, P. Ares, A. Janardanan, Q. Yang, B. Radha, T. Taniguchi, K. Watanabe, G. Gomila, K. S. Novoselov, and A. K. Geim, Science 360, 1339 (2018).

${ }^{29}$ M. R. Reddy and M. Berkowitz, Chem. Phys. Lett. 155, 173 (1989).

${ }^{30} \mathrm{M}$. Neumann, J. Chem. Phys. 85, 1567 (1986).

${ }^{31}$ J. L. F. Abascal and C. Vega, J. Chem. Phys. 123, 234505 (2005).

${ }^{32}$ C. Vega and J. L. F. Abascal, Phys. Chem. Chem. Phys. 13, 19663 (2011).

${ }^{33}$ C. Vega, Mol. Phys. 113, 1145 (2015).

${ }^{34}$ D. Horinek, S. I. Mamatkulov, and R. R. Netz, J. Chem. Phys. 130, 124507 (2009).

${ }^{35}$ K. P. Jensen and W. L. Jorgensen, J. Chem. Theory Comput. 2, 1499 (2006).

${ }^{36}$ M. M. Reif and P. H. Hünenberger, J. Chem. Phys. 134, 144103 (2011).

${ }^{37}$ I. S. Joung and T. E. Cheatham III, J. Phys. Chem. B 112, 9020 (2008).

${ }^{38}$ M. Fyta, I. Kalcher, J. Dzubiella, L. Vrbka, and R. R. Netz, J. Chem. Phys. 132, 024911 (2010).

${ }^{39}$ M. Fyta and R. R. Netz, J. Chem. Phys. 136, 124103 (2012).

${ }^{40}$ S. Deublein, J. Vrabec, and H. Hasse, J. Chem. Phys. 136, 084501 (2012).

${ }^{41}$ S. Reiser, S. Deublein, J. Vrabec, and H. Hasse, J. Chem. Phys. 140, 044504 (2014).

${ }^{42}$ S. Weerasinghe and P. E. Smith, J. Chem. Phys. 119, 11342 (2003).

${ }^{43}$ M. B. Gee, N. R. Cox, Y. Jiao, N. Bentenitis, S. Weerasinghe, and P. E. Smith, J. Chem. Theory Comput. 7, 1369 (2011).

${ }^{44}$ A. H. Mao and R. V. Pappu, J. Chem. Phys. 137, 064104 (2012).

${ }^{45}$ I. Nezbeda, F. Moučka, and W. R. Smith, Mol. Phys. 114, 1665 (2016). 
${ }^{46}$ F. Moučka, I. Nezbeda, and W. R. Smith, J. Chem. Phys. 138, 154102 (2013).

${ }^{47}$ J. S. Kim, Z. Wu, A. R. Morrow, A. Yethiraj, and A. Yethiraj, J. Phys. Chem. B 116, 12007 (2012).

${ }^{48}$ F. Moučka, I. Nezbeda, and W. R. Smith, J. Chem. Theory Comput. 11, 1756 (2015).

${ }^{49}$ M. Kohns, M. Schappals, M. Horsch, and H. Hasse, J. Chem. Eng. Data 61, 4068 (2016).

${ }^{50}$ I. S. Joung and T. E. Cheatham III, J. Phys. Chem. B 113, 13279 (2009).

${ }^{51}$ A. L. Benavides, J. L. Aragones, and C. Vega, J. Chem. Phys. 144, 124504 (2016).

${ }^{52}$ A. L. Benavides, M. A. Portillo, J. L. F. Abascal, and C. Vega, Mol. Phys. 115, 1301 (2017).

${ }^{53}$ F. Moučka, M. Lísal, J. Škvor, J. Jirsák, I. Nezbeda, and W. R. Smith, J. Phys. Chem. B 115, 7849 (2011).

${ }^{54}$ Z. Mester and A. Z. Panagiotopoulos, J. Chem. Phys. 143, 044505 (2015).

${ }^{55}$ E. Wernersson and P. Jungwirth, J. Chem. Theory Comput. 6, 3233 (2010).

${ }^{56}$ J. Alejandre and J.-P. Hansen, Phys. Rev. E 76, 061505 (2007).

${ }^{57}$ A. A. Chen and R. V. Pappu, J. Phys. Chem. B 111, 6469 (2007).

${ }^{58}$ P. Auffinger, T. E. Cheatham III, and A. C. Vaiana, J. Chem. Theory Comput. 3, 1851 (2007).

${ }^{59}$ B. Giri and E. Spohr, J. Mol. Liq. 228, 63 (2017).

${ }^{60}$ J. Alejandre, G. A. Chapela, F. Bresme, and J.-P. Hansen, J. Chem. Phys. 130, 174505 (2009)

${ }^{61}$ A. A. Chen and R. V. Pappu, J. Phys. Chem. B 111, 11884 (2007).

${ }^{62}$ F. Moučka, I. Nezbeda, and W. R. Smith, J. Chem. Theory Comput. 9, 5076 (2013).

${ }^{63}$ B. Eckl, J. Vrabec, and H. Hasse, Fluid Phase Equilib. 274, 16 (2008).

${ }^{64}$ R. Fuentes-Azcatl and J. Alejandre, J. Phys. Chem. B 118, 1263 (2014).

${ }^{65}$ J. Alejandre, G. A. Chapela, H. Saint-Martin, and N. Mendoza, Phys. Chem. Chem. Phys. 13, 19728 (2011).

${ }^{66}$ I. V. Leontyev and A. A. Stuchebrukhov, J. Chem. Phys. 130, 085102 (2009).

${ }^{67}$ W. R. Smith, I. Nezbeda, J. Kolafa, and F. Moučka, Fluid Phase Equilib. 466, 19 (2018).

${ }^{68}$ J. Sala, E. Guàrdia, and J. Martí, J. Chem. Phys. 132, 214505 (2010).

${ }^{69}$ A. Y. Zasetsky and I. M. Svishchev, J. Chem. Phys. 115, 1448 (2001).

${ }^{70}$ I. Pethes, J. Mol. Liq. 242, 845 (2017).

${ }^{71}$ D. Pache and R. Schmid, ChemElectroChem 5, 1444 (2018).

${ }^{72}$ S. Seal, K. Doblhoff-Dier, and J. Meyer, J. Phys. Chem. B 123, 9912 (2019).

${ }^{73}$ S. Reiser, M. Horsch, and H. Hasse, J. Chem. Eng. Data 60, 1614 (2015).

${ }^{74}$ S. Reiser, M. Horsch, and H. Hasse, Fluid Phase Equilib. 408, 141 (2016).

${ }^{75}$ M. Kohns, M. Horsch, and H. Hasse, Fluid Phase Equilib. 458, 30 (2018).
${ }^{76}$ H. W. Horn, W. C. Swope, J. W. Pitera, J. D. Madura, T. J. Dick, G. L. Hura, and T. Head-Gordon, J. Chem. Phys. 120, 9665 (2004).

${ }^{77}$ F. Moučka, M. Lísal, and W. R. Smith, J. Phys. Chem. B 116, 5468 (2012).

${ }^{78}$ J. L. Aragones, M. Rovere, C. Vega, and P. Gallo, J. Phys. Chem. B 118, 7680 (2014).

${ }^{79}$ S. Deublein, B. Eckl, J. Stoll, S. V. Lishchuk, G. Guevara-Carrion, C. W. Glass, T. Merker, M. Bernreuther, H. Hasse, and J. Vrabec, Comput. Phys. Commun. 182, 2350 (2011).

${ }^{80}$ C. W. Glass, S. Reiser, G. Rutkai, S. Deublein, A. Köster, G. Guevara-Carrion, A. Wafai, M. Horsch, M. Bernreuther, T. Windmann, H. Hasse, and J. Vrabec, Comput. Phys. Commun. 185, 3302 (2014).

${ }^{81}$ G. Rutkai, A. Köster, G. Guevara-Carrion, T. Janzen, M. Schappals, C. W. Glass, M. Bernreuther, A. Wafai, S. Stephan, M. Kohns, S. Reiser, S. Deublein, M. Horsch, H. Hasse, and J. Vrabec, Comput. Phys. Commun. 221, 343 (2017).

${ }^{82}$ H. Flyvbjerg and H. G. Petersen, J. Chem. Phys. 91, 461 (1989).

${ }^{83}$ S. W. D. Leeuw, J. W. Perram, and E. R. Smith, Proc. R. Soc. London, Ser. A 388, 177 (1983).

${ }^{84}$ S. W. De Leeuw, J. W. Perram, and E. R. Smith, Annu. Rev. Phys. Chem. 37, 245 (1986).

${ }^{85}$ Y. Marcus, J. Solution Chem. 42, 2354 (2013).

${ }^{86}$ J. Vincze, M. Valiskó, and D. Boda, J. Chem. Phys. 133, 154507 (2010).

${ }^{87}$ S. Reiser, M. Horsch, and H. Hasse, J. Chem. Eng. Data 59, 3434 (2014).

${ }^{88} \mathrm{~J}$. G. Méndez-Bermúdez, H. Dominguez, L. Pusztai, S. Guba, B. Horváth, and I. Szalai, J. Mol. Liq. 219, 354 (2016).

${ }^{89}$ R. Fuentes-Azcatl and M. C. Barbosa, J. Phys. Chem. B 120, 2460 (2016).

${ }^{90}$ W. R. P. Scott, P. H. Hünenberger, I. G. Tironi, A. E. Mark, S. R. Billeter, J. Fennen, A. E. Torda, T. Huber, P. Krüger, and W. F. van Gunsteren, J. Phys. Chem. A 103, 3596 (1999).

${ }^{91}$ M. Sega, S. S. Kantorovich, C. Holm, and A. Arnold, J. Chem. Phys. 140, 211101 (2014).

${ }^{92}$ S. Koneshan and J. C. Rasaiah, J. Chem. Phys. 113, 8125 (2000).

${ }^{93}$ R. Hartkamp and B. Coasne, J. Chem. Phys. 141, 124508 (2014).

${ }^{94}$ C. J. Fennell, A. Bizjak, V. Vlachy, and K. A. Dill, J. Phys. Chem. B 113, 6782 (2009).

${ }^{95}$ K. D. Collins, Biophys. J. 72, 65 (1997).

${ }^{96}$ E. Sanz and C. Vega, J. Chem. Phys. 126, 014507 (2007).

${ }^{97}$ A. L. Benavides, M. A. Portillo, V. C. Chamorro, J. R. Espinosa, J. L. F. Abascal, and C. Vega, J. Chem. Phys. 147, 104501 (2017).

${ }^{98}$ I. M. Zeron, J. L. F. Abascal, and C. Vega, J. Chem. Phys. 151, 134504 (2019).

${ }^{99} \mathrm{R}$. Fuentes-Azcatl and M. C. Barbosa, Physica A 491, 480 (2018).

${ }^{100} \mathrm{H}$. Jiang and A. Z. Panagiotopoulos, J. Chem. Phys. 145, 046101 (2016). 